\title{
POKA YOKE: DESENVOLVIMENTO DE UM SISTEMA SELETOR DE FRUTAS
}

\author{
Cicera R. Janneally de S. Fernandes (UFCG) janneallyfernandes13@hotmail.com \\ Laiany E. Borges Rodrigues (UFCG) laianybr@gmail.com \\ Nicole Lustosa de Andrade Siqueira (UFCG) nicolealustosa@gmail.com
}

\begin{abstract}
Resumo
A ferramenta Poka Yoke é uma palavra de origem japonesa, assim como $5 \mathrm{~S}$ e Kaizen, e tem como significado "A prova de erros", ou seja, sistema criado com o intuito de prevenir falhas humanas. Podendo ainda ser considerada uma aliada para a melhoria contínua, atuando na manutenção e inspeção da qualidade de produtos. Proporciona a padronização, otimizando a produção e eliminando eventuais desníveis no setor de produtividade. É um excelente método para as organizações manter níveis de excelência operacional e manter-se à frente no mercado competitivo, pois é eficaz na redução de custos. Buscando minorar o máximo possível os produtos defeituosos que são acometidos por falhas no processo mediante atuação humana. Visto que, com pesquisas de mercado, é possível encontrar em muitos estabelecimentos ações que acometem o produto e que, por ventura, causam retrabalho e gasto desnecessário foi-se então estudado com mais detalhes a ferramenta em questão e desenvolvido um método antifalhas para prevenção dos erros citados a cima. O objetivo deste trabalho é alcançar e proporcionar agilidade e um maior grau de excelência na separação de produtos.
\end{abstract}

Palavras-chaves: Poka Yoke; Qualidade; Desperdícios; Falha Humana.

\section{Introdução}

Reconhecendo a incessante necessidade de melhorar processos e proporcionar um nível de Qualidade à produção e produtos, faz-se necessário ter conhecimento e aprimorar-se de ferramentas que auxiliam na manutenção desses fatores, já que nos dias de hoje, a voz do cliente tem sido prioridade no mercado. Trabalha-se para manter um nível de excelência operacional a fim de eliminar, ou diminuir, desperdícios e retrabalhos, atividades que não agregam valor. 
Com base nesse crescimento acelerado do mercado e exigência por produtos com qualidade (levando em consideração que qualidade é relativa e dá-se então atenção às demandas exigidas de cada cliente), a aplicação de uma ferramenta que seja capaz de minimizar erros é necessária. No sistema Toyota de produção, na década de 60 no Japão, foi desenvolvido o Poka Yoke um sistema antifalhas humanas, tal que proporciona a diminuição de custos eliminando falhas e minimizando o lead time.

Propôs-se então um estudo qualitativo sobre a ferramenta para obter conhecimento prévio antes de desenvolver o projeto que tem como finalidade a elaboração de um Poka Yoke em uma organização para garantir maior eficiência no momento de separar os produtos.

\section{Referencial teórico}

Neste tópico ressalta-se o embasamento teórico da ferramenta Poka Yoke, assim como todos os termos que se fizeram necessários no ato da pesquisa para conhecimento das definições para então aplicá-la de forma prática a um estabelecimento real.

\subsection{Sistema toyota de produção}

Sistema de produção desenvolvido pela Toyota Motor Corporation, que se deu por uma combinação dos princípios de técnicas de qualidade, que diminui desperdícios e fornece o lead time mais curto por meio da eliminação do desperdício. O STP foi inspirado nos mecanismos de Henry Ford e Frederick Taylor. Segundo Maximiano (2005) os dois principais objetivos do sistema Toyota são: Eliminação de erros e fabricação com qualidade.

De acordo com Shingo (1989), o STP tem a função de detectar totalmente os desperdícios, as principais perdas são ocasionadas por: superprodução; tempo de espera; transporte; estoque disponível; e produção de produtos defeituosos. O Sistema Toyota aplica três ideias principais para eliminação de desperdícios: racionalização da força de trabalho, Just in time e produção flexível.

A produção com Qualidade tem o propósito de identificar e reparar defeitos, tendo assim o objetivo de eliminar os desperdícios. Portanto o controle da qualidade realizado pelos inspetores no fim da produção torna-se supérfluo tendo assim mais um fator de desperdício a ser eliminado. 


\subsection{Melhoria contínua}

A ideia de melhoria contínua está relacionada à capacidade de resolução de problemas, reduzindo erros e aumentando a qualidade. O método de resolução de problemas é organizado em partes como a identificação das causas, escolha, planejamento e padronização da solução. A melhoria é continua porque o ciclo de reparação de erros é realizado indefinidamente para encontrar uma solução ou aperfeiçoar algo já obtido.

O ciclo PDCA é um método que permite que esforços sistemáticos e iterativos de melhoria sejam levados a cabo. Por sua vez, existem três tipos de melhoria: controle de processo, melhoria reativa e melhoria pró-ativa ( SHIBA, 1997 ).

Além do ciclo PDCA, também pode-se evidenciar o método Kaizen. De origem japonesa, expressão que significa exatamente "melhoria". Essa concepção interpreta um empenho contínuo entre todas as funções de todos os níveis de uma empresa.

Para ser efetiva, a melhoria contínua precisa ser administrada como um processo estratégico com foco no longo prazo ( BESSANT, 1994 ). As organizações que se destacam na melhoria contínua incorporam-na em seus valores e a refletem em sua contratação e treinamento. Eles também incorporam em seu sistema de avaliação e compensação de funcionários.

\subsection{Ferramenta PokaYoke}

Os mecanismos ou dispositivos Poka Yoke são também denominados de mecanismos de prevenção de erro ou a prova de falha; têm sua origem na língua japonesa das palavras yokeru (evitar) e poka (erro inadvertido) e são utilizados há muito tempo pela indústria manufatureira japonesa (CARLAGE; DAVANSO, 2001).

Existem quatro modalidades do método que podem ser utilizadas em processos da produção para prevenir erros ou evita-los são elas: Prevenção (que tende a eliminar de vez a causa raiz do problema, que em muitos casos pode estar relacionada com excesso de atividades, rotatividade de funcionários no posto de trabalho, ambiente desorganizado e falta de treinamento adequado), Detecção (através do controle e da advertência consegue-se impedir que o processo seja finalizado de forma errônea, obrigando o mesmo a ser corrigido na sua fonte e que sejam sinalizados por meio de sinais visuais e auditivos sobre erros consequentemente), Valor Fixo (através dessa modalidade pode se garantir que um número x 
de movimentos podem ter sido realizados durante o processo proposto), e Etapas (nessa última modalidade o objetivo é evitar falhas na operação, permitindo que todo processo seja seguido uma sequência correta, caso isso não aconteça não é possível chegar a operação final.)

\section{Metodologia}

Adotou-se o método de pesquisa qualitativa com embasamento na criação de um objeto cuja finalidade é fazer a seleção por tamanho de produtos ofertados em feiras de rua/casas de venda de frutas, visto que há um atraso no processo em separá-los por tamanho ou ainda os clientes no momento da compra passam mais tempo selecionando e tentando diferenciar qual o maior ou menor produto. Ou seja, não há uma padronização, o que demanda um maior tempo de escolha e seleção.

A pesquisa foi realizada em um estabelecimento comercial de frutas e legumes e notou-se a necessidade de um método que minimizasse a falta de padrão e ofertasse melhora instantânea no processo de separação do item, proporcionando uma maior eficiência no processo e ainda o feito de poder cobrar pelo produto com base em seu tamanho, já que antes o valor cobrado era o mesmo para ambos tamanhos (pequenos ou grandes), o que de fato não agregava valor no momento da compra dos clientes. Logo, a proposta foi desenvolver um sistema Poka Yoke para seleção de frutas, um produto que seja portátil, leve e de fácil utilização podendo ser usado para a seleção de qualquer fruta desde que seja arredondada, tais como limão, laranja, cebolas e tomates. Os orifícios desse novo produto antierro serão feitos de acordo com a fruta escolhida e o padrão desejado para a seleção pelo proprietário do local, ou seja, é um item que poderá sofrer alterações, em relação ao tamanho dos orifícios, em sua fabricação de acordo com a fruta desejada.

\section{Desenvolvimento}

Após realizar todas as observações no campo de aplicação da pesquisa, identificar os erros e necessidades existentes, foi projetado um dispositivo cuja finalidade é a separação por tamanho de frutas, foi-se então estudado detalhes e analisado a possível eficácia do sistema. Com isso foi apresentado o sistema aos colaboradores do estabelecimento estudado e constatada a aceitação caso sucedesse de ali instalar.

Destinou-se todo o conhecimento adquirido no ato da pesquisa em prol da criação de um item que intervisse de forma correta e sem desperdícios, apresentando uma padronização do produto. Durante as visitas foram realizadas entrevistas com toda a equipe do local a fim de 
obter informações mais precisas sobre qual produto oferecido no estabelecimento oferecia um maior grau de desigualdade em questão do tamanho em função do preço.

Após algumas visitações, por meio de anotações e observações, percebeu-se que muitos clientes gastavam muito tempo quando estavam escolhendo os limões, laranjas, tomates e até mesmo cebolas, passando um maior período analisando a custo benefício do item a ser comprado de acordo com o tamanho do mesmo.

Mesmo alguns preferindo os menores, escolhiam o de maior tamanho e alegavam que em função do custo da fruta os maiores apresentavam maior vantagem de custo-benefício e acabavam adquirindo o produto por este motivo.

A partir daí, observou-se que o período escolhendo o de maior tamanho para sair na vantagem era grande, alguns gastavam mais tempo nos limões e laranjas do que escolhendo quaisquer outros produtos que apresentavam tamanho mais padronizado uns com os outros.

Outra observação bastante relevante, é que, o primeiro que saia eram os de tamanho grande, consequentemente os que possuíam medida pequena a olho nu em comparação com os demais, eram deixados na prateleira e lá permaneciam até que os maiores já tivessem esgotados. Essa prática nos leva a perda de produtos, pois dependendo do tempo ali exposto acabavam estragando e tendo que ser descartados.

Outra prática de desperdícios é que muitas vezes era reposto mais frutas "em cima" dos antigos e pequenos, fazendo com que os clientes buscassem pelos mais novos e maiores, mais uma vez. Um ciclo repetitivo.

Por questões diversas, inclusive o tempo exigido para tal ação, a empresa abordada não faz o uso de seleção manual, expondo desta forma os produtos misturados e sem padronização.

Pontuou-se então o levantamento desses dados e foi feita uma reunião com os colaboradores do estabelecimento para informar sobre as observações feitas. Acataram a ideia de que era necessário um dispositivo que separasse com maior rapidez as frutas que agora passariam a ter valores diferentes referentes ao tamanho, pequenos e grandes.

\subsection{Máquina portátil para separação de frutas}

O dispositivo Poka Yoke aqui idealizado tem como objetivo separar as frutas, que necessitam ter forma esférica, por meio do movimento giratório de um cilindro preenchido por aberturas, onde permite que a fruta escape. 
O cilindro possui três níveis de furo, sendo eles de diâmetros diferentes e de acordo com o tipo de fruta alvo da seleção. Os furos devem ser dispostos no cilindro na ordem do pequeno para o grande.

Imagem 1 - Máquina separadora de frutas esféricas

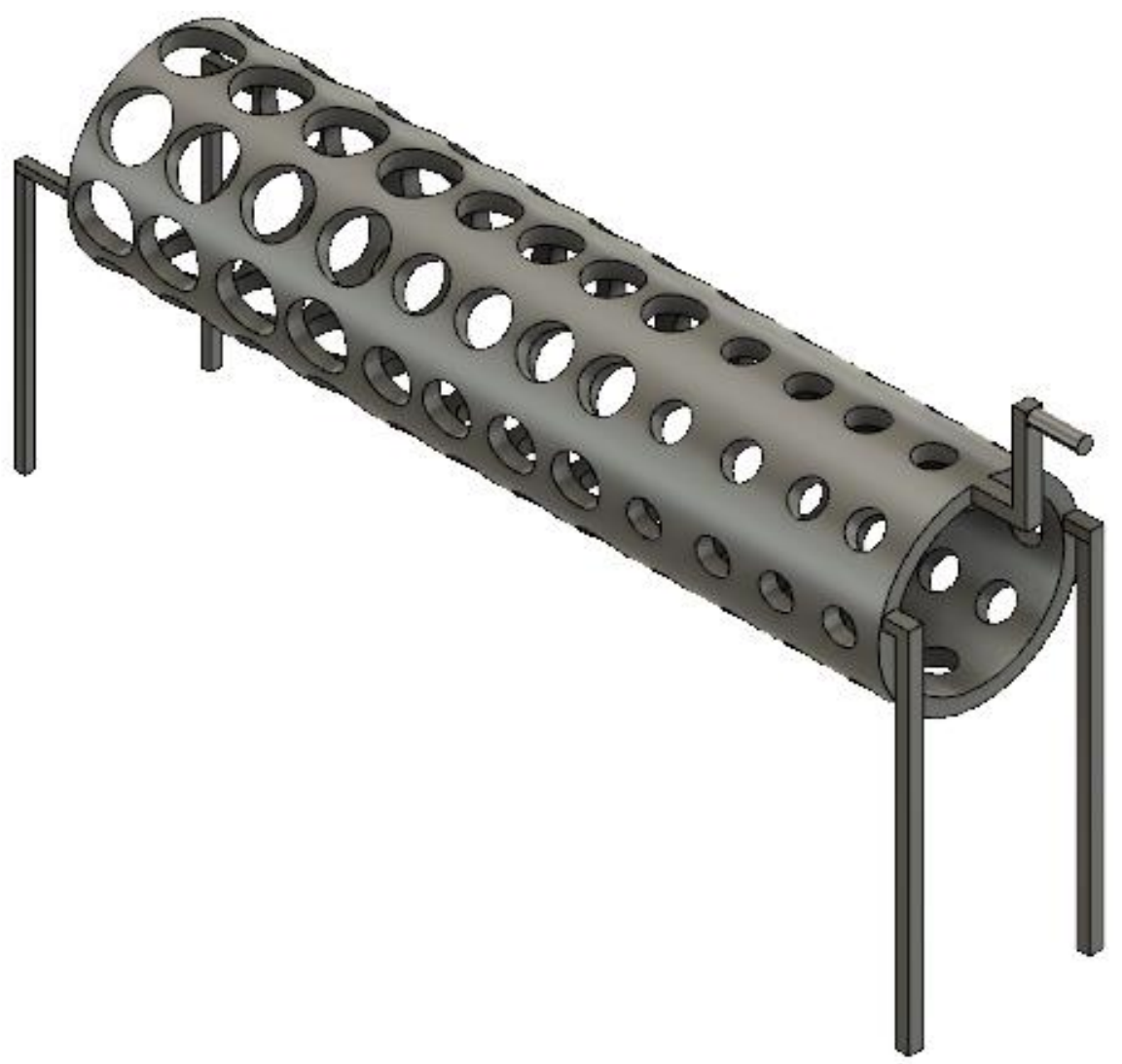

Fonte: Autoria própria (2020)

O separador possui cilindro plástico, onde trás maior leveza para o produto. Em sua parte interna, se faz necessário adicionar um revestimento de borracha para que as frutas não sejam machucadas com o atrito feito pelo movimento da máquina.

Já seu suporte deve ser confeccionado com um metal leve, como o alumínio. A manivela e seu eixo devem ser constituídos de plástico e alumínio também.

O cilindro tem 1,20 metros de extensão e 30 centímetros de diâmetro, sendo assim um dispositivo de fácil locomoção em comparação a máquinas de grande escala. Abaixo dele será encaixada uma caixa com três compartimentos para que as frutas caiam dentro. 


\section{Imagem 2 - Caixa coletora}

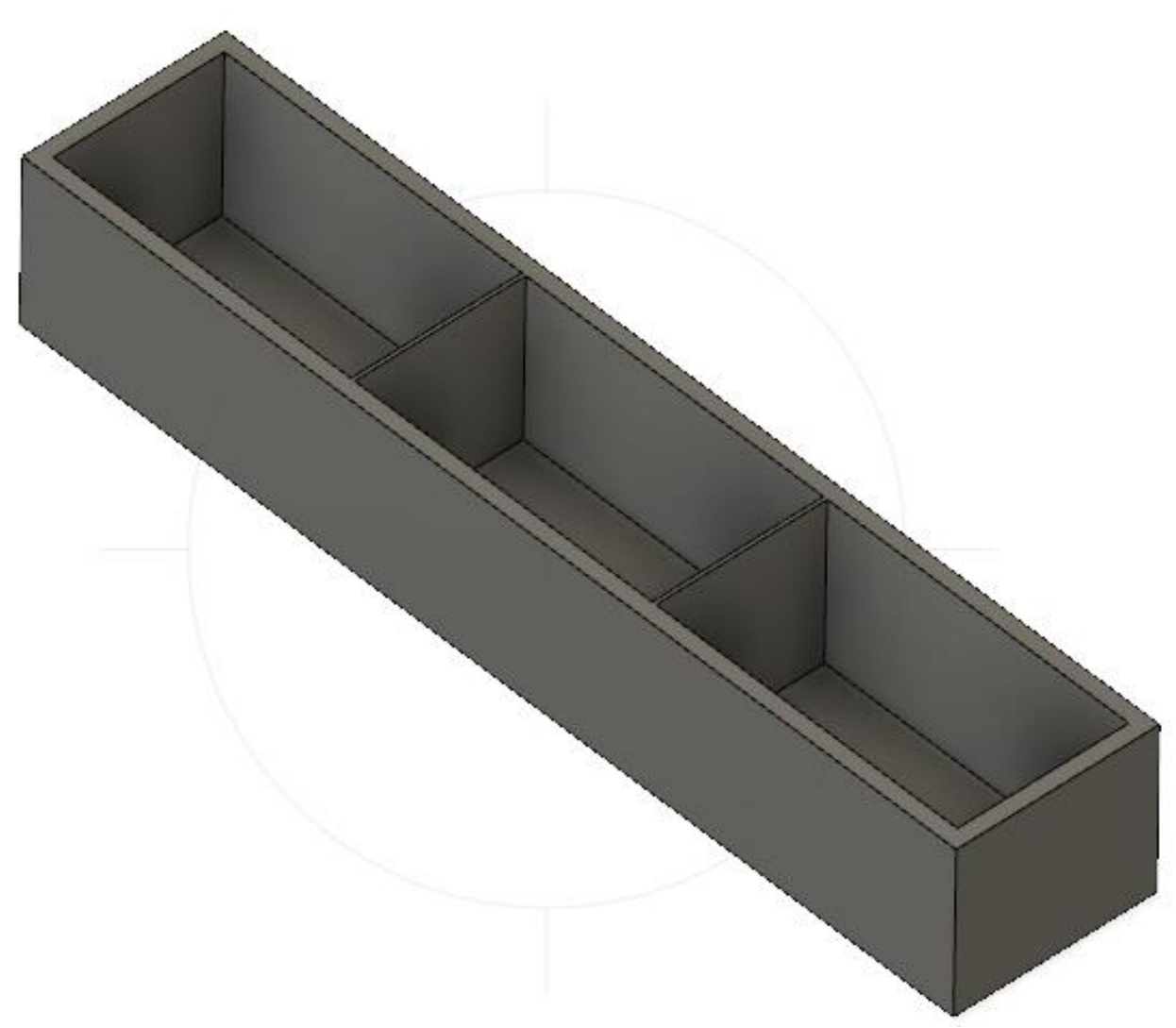

Fonte: Autoria própria (2020)

O cilindro pode ser desencaixado da base para que assim possa encaixar diversos tipos de cilindro com furos de acordo com diversos tipos de frutas, ampliando assim a aplicação dentro da empresa.

A funcionalidade do produto ocorre da seguinte forma: Com a assistência das mãos as frutas são adicionadas dentro do cilindro, no sentido do furo menor para o maior. Com as mãos e com movimentos leves gira-se o cilindro com o auxílio da manivela, fazendo com que dessa forma as frutas se movimentem no interior e caiam pelas aberturas de acordo com seu tamanho. No primeiro nível caem apenas as frutas menores que possuem diâmetro igual ou inferior ao furo, as frutas que não passaram seguem para próxima etapa onde os furos são um pouco maiores, e da mesma forma caem apenas as frutas correspondentes ao diâmetro dos 
orifícios, e assim segue até todas as frutas caírem na caixa que está abaixo do rolo. Caso sobre alguma fruta que não passou por nenhum dos furos com o auxílio das mãos é feita a retirada. A confecção do protótipo real não foi possível por conta que seria inviável devido a inexistência de profissionais que trabalhem com os materiais idealizados. Neste caso um desenho que esboçasse a ideia e que mostrasse claramente o dispositivo foi a melhor opção. Ainda assim alguns detalhes não estão presentes nas imagens, como o eixo central.

\section{Resultados e discussão}

Os resultados esperados dentro das possibilidades foram bons, pois teoricamente atende as expectativas propostas. A funcionalidade na prática da máquina desenvolvida não foi testada, pois foi feito apenas um protótipo em desenho para se ter ideia de como seria o item final. A intenção é que haja um direcionamento maior dos clientes já em direção ao tamanho das frutas que lhe seja conveniente, poupando-lhes tempo no momento da seleção. Outra medida esperada é que depois da padronização das frutas e por apresentarem posteriormente preço em função do tamanho, elas saiam do estoque quase que proporcionalmente, isso leva a menos desperdícios e menos frutas estragadas. Nota-se que, de fato, a ferramenta Poka Yoke é passível de mudanças, poupando tempo e causando menos desperdícios.

\section{Considerações finais}

Visto que cada vez mais as empresas buscam a melhoria dos seus processos, e que o sistema Poka Yoke busca corrigir possíveis erros, despadronização e assegurar que exista apenas um meio de realizar determinada ação, pode-se afirmar que o objetivo proposto foi cumprido de acordo com o esperado. O seletor aqui desenvolvido traz uma aplicação prática, porém com grandes resultados.

Acredita-se que a execução do dispositivo proporcionará resultados mais duradouros a longo prazo para a empresa. Notou-se que a equipe de trabalho da organização depois das visitas passou a ter um olhar mais crítico para com os produtos tentando estar sempre atento se a ordem de saída dos produtos está acontecendo de forma correta, primeiro que entra, primeiro que sai. Por se tratar de produtos perecíveis esse olhar mais detalhado das vendas é bastante relevante.

Podendo posteriormente desenvolver outro artifício para melhorar outro tipo de processo ou produto ofertado.

\section{REFERÊNCIAS}


BESSANT, J.; CAFFYN, S.; GILBERT, J.; HARDING R; WEBB, S. Rediscoveringcontinuousimprovement. Technovation. v. 14, n. 1, p. 17-29, 1994.

MAXIMIANO, A.: Teoria Geral da Administração: da revolução urbana à revolução digital. 5.ed - São Paulo: Atlas,2005.

SHINGO, S.: Sistemas de Produção com Estoque Zero: O Sistema Shingo para Melhorias Contínuas. Bookman, Porto Alegre, RS, 1989

SHIBA, S; GRAHAM, A.; WALDEN, D. TQM: quatro revoluções na gestão da qualidade. Artes Médicas: Porto Alegre, 1997.

Sistema Toyota de Produção (Toyota Production System - TPS). Disponível em:

<https://www.lean.org.br/conceitos/117/sistema-toyota-de-producao-(toyota-production-system---tps).aspx>.

Acessado em 03 de dezembro de 2019.

Gonçalves, Victor. Melhoria contínua: o que é e como fazer?,2018. Disponível em: <https://www.voitto.com.br/blog/artigo/melhoria-continua>. Acessado em 03 de dezembro de 2019.

CARlage, F. A; DAVAnSO, J. C. A Utilização de Dispositivos à Prova de Erros: Poka-Yoke Empregado na Melhoria de Desempenho de Processos de Manufatura. Conferência Brasileira de Engenharia de Manutenção,2001.

Redação indústria hoje, O que é Poka Yoke?,2013 Disponível em:<https://industriahoje.com.br/o-que-e-pokayoke>.Acessado em 03 de dezembro de 2019. 